\title{
High BAALC copy numbers in peripheral blood prior to allogeneic transplantation predict early relapse in acute myeloid leukemia patients
}

\author{
Madlen Jentzsch ${ }^{1}$, Marius Bill ${ }^{1}$, Juliane Grimm ${ }^{1}$, Julia Schulz ${ }^{1}$, Karoline Goldmann ${ }^{1}$, \\ Stefanie Beinicke ${ }^{1}$, Janine Häntschel ${ }^{1}$, Wolfram Pönisch ${ }^{1}$, Georg-Nikolaus Franke ${ }^{1}$, \\ Vladan Vucinic ${ }^{1}$, Gerhard Behre ${ }^{1}$, Thoralf Lange ${ }^{1}$, Dietger Niederwieser ${ }^{1}$ and \\ Sebastian Schwind ${ }^{1}$ \\ ${ }^{1}$ Department of Hematology and Oncology, University of Leipzig, Leipzig, Germany \\ Correspondence to: Sebastian Schwind, email: sebastian.schwind@medizin.uni-leipzig.de \\ Keywords: acute myeloid leukemia, allogeneic stem cell transplantation, residual disease, BAALC, prognosis \\ Received: July 18, $2017 \quad$ Accepted: August 17, $2017 \quad$ Published: September 27, 2017 \\ Copyright: Jentzsch et al. This is an open-access article distributed under the terms of the Creative Commons Attribution License \\ 3.0 (CC BY 3.0), which permits unrestricted use, distribution, and reproduction in any medium, provided the original author and \\ source are credited.
}

\section{ABSTRACT}

High BAALC expression levels at acute myeloid leukemia diagnosis have been linked to adverse outcomes. Recent data indicate that high BAALC expression levels may also be used as marker for residual disease following acute myeloid leukemia treatment. Allogeneic hematopoietic stem cell transplantation (HSCT) offers a curative treatment for acute myeloid leukemia patients. However, disease recurrence remains a major clinical challenge and identification of high-risk patients prior to HSCT is crucial to improve outcomes. We performed absolute quantification of BAALC copy numbers in peripheral blood prior (median 7 days) to HSCT in complete remission (CR) or CR with incomplete peripheral recovery in 82 acute myeloid leukemia patients using digital droplet PCR (ddPCR) technology. An optimal cut-off of 0.14 BAALC/ABL1 copy numbers was determined and applied to define patients with high or low BAALC/ABL1 copy numbers. High pre-HSCT BAALC/ABL1 copy numbers significantly associated with higher cumulative incidence of relapse and shorter overall survival in univariable and multivariable models. Patients with high pre-HSCT BAALC/ABL1 copy numbers were more likely to experience relapse within 100 days after HSCT. Evaluation of pre-HSCT BAALC/ABL1 copy numbers in peripheral blood by ddPCR represents a feasible and rapid way to identify acute myeloid leukemia patients at high risk of early relapse after HSCT. The prognostic impact was also observed independently of other known clinical, genetic, and molecular prognosticators. In the future, prospective studies should evaluate whether acute myeloid leukemia patients with high preHSCT BAALC/ABL1 copy numbers benefit from additional treatment before or early intervention after HSCT.

\section{INTRODUCTION}

The identification of cytogenetic, molecular, and clinical factors impacting on outcome at acute myeloid leukemia (AML) diagnosis improved risk stratification $[1,2]$. But pre-treatment AML characterization may not capture all parameters important for outcome, e.g. response or resistance to therapy [3]. Early detection of measurable residual disease (MRD) through multiparameter flow cytometric (MFC) or quantitative real time PCR (qRT-PCR) assays may allow treatment intervention before overt relapse occurs [3-5]. MFC enables MRD assessment through detection of aberrant surface antigen expression in complete remission (CR) [Wormann et al, ASH 1991, 6, 7]. However, heterogenic outcomes were observed in MFC-MRD studies [8] and 
reproducibility of MFC-MRD assessment is limited by the need of specialized laboratories [3, 4]. Sensitive qRTPCR enabled MRD detection in AML cases with common fusion genes and in NPM1 mutated AML [3, 9, 10]. Thus qRT-PCR MRD monitoring is widely restricted to patients carrying specific molecular alterations [11] with the exception of Wilms' tumor gene 1 (WT1) expression $[9,12]$. Because clonal evolution can occur at disease progression and might complicate early disease detection at relapse [13], it seems reasonable to track several MRD markers per patient.

The gene brain and acute leukemia, cytoplasmic $(B A A L C)$ has been suggested as a suitable MRD marker as it is expressed at low levels in peripheral blood and bone marrow of healthy individuals $[14,15]$, but upregulated in AML patients [15]. High BAALC expression levels at AML diagnosis have been shown to associate with adverse outcomes [16-19]. Recently, high BAALC levels have also been linked to worse outcome if measured by qRT-PCR after achievement of CR [15], completion of induction therapy $[11,20]$ or after allogeneic stem cell transplantation (HSCT) [21]. However, qRT-PCR has the disadvantage of the need of calibration curves and poor inter-laboratory comparability. In chronic myeloid leukemia (CML) this led to complex harmonization efforts for $B C R-A B L 1$ detection [22], which are not yet clinical practice for MRD markers in AML. Here we adopted digital droplet PCR (ddPCR), a new technique which allows an absolute quantification without the need of standard curves [23].
Allogeneic HSCT is a potential curative treatment option for AML patients and offers the highest chance of sustained remissions [2]. Non-myeloablative conditioning regimens (NMA), in which the therapeutic success is mainly based on graft-versus-leukemia (GvL) effects, enabled allogeneic HSCT in comorbid or older individuals [24]. Disease recurrence after HSCT remains a major clinical problem with short patient survival [25]. Until today, no study evaluated the feasibility of $B A A L C$ expression levels for risk stratification in AML patients prior to allogeneic HSCT in CR or CR with incomplete peripheral recovery (CRi), which was the main objective of our study. Early identification of AML patients at high risk of relapse may result in adjustment of treatment strategies prior to morphologic relapse and subsequently improve outcomes. With the goal of a robust, rapid, and reproducible approach, we used peripheral blood to assess the feasibility of ddPCR for absolute quantification of $B A A L C / A B L 1$ copy numbers.

\section{RESULTS}

\section{$B A A L C / A B L 1$ copy numbers in AML patients prior to HSCT and in healthy individuals}

Within the patient cohort in $\mathrm{CR}$ or $\mathrm{CRi}$ prior to HSCT, we observed a median pre-HSCT BAALC/ABL1 copy number of 0.03 (range 0.00-2.58, Figure 1). In the healthy control cohort, median $B A A L C / A B L 1$ copy numbers were 0.04 (range 0.03-0.10). Overall, there was no significant difference in the $B A A L C / A B L 1$ copy

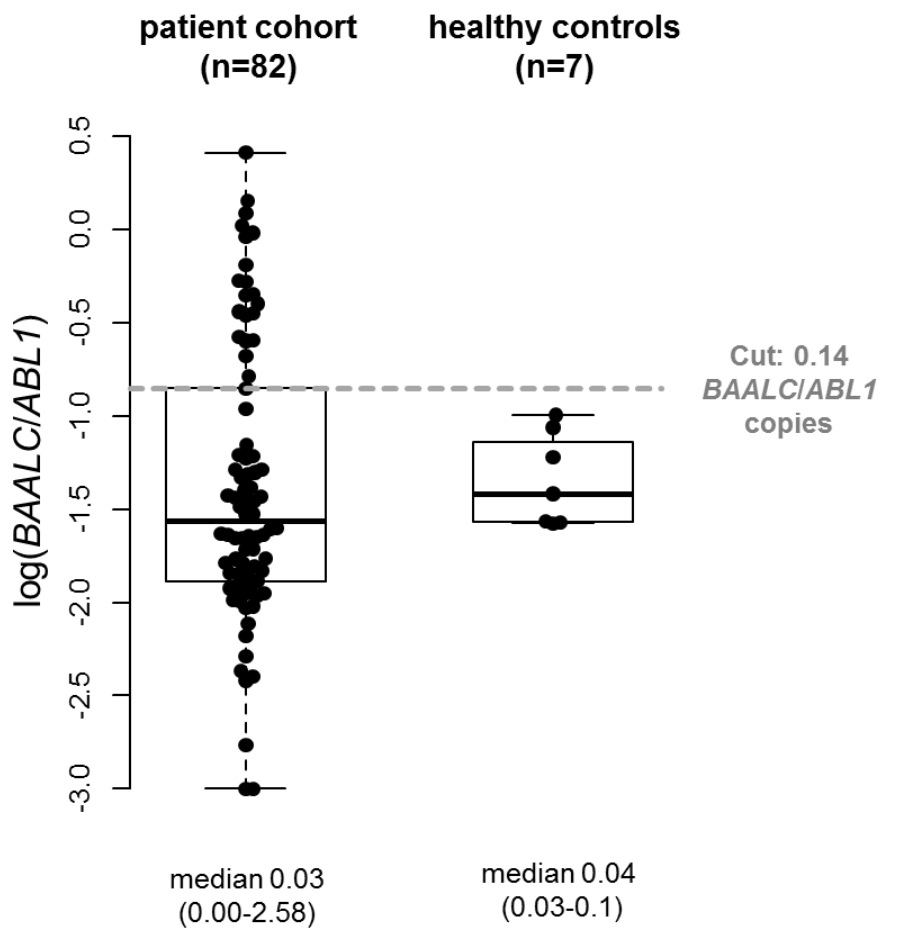

Figure 1: Comparison of absolute $B A A L C / A B L 1$ copy numbers in AML patients pre-HSCT (n=82) and healthy controls $(\mathbf{n}=7)$. 
numbers between both groups $(P=.34)$. The patient cohort and the healthy control cohort were evenly matched in age $(P=1)$ and $\operatorname{sex}(P=1$, Supplementary Table 2$)$.

\section{Associations of high pre-HSCT $B A A L C / A B L 1$ copy numbers with clinical and biological characteristics}

Patients with high and low pre-HSCT BAALC/ABL1 copy numbers did not differ significantly in the evaluated characteristics at diagnosis (Table 1, Supplementary Table 1). However, there was a trend for a lower incidence of $C E B P A$ mutations in patients with high pre-HSCT BAALC/ABL1 copy numbers $(P=.09)$. Patients with high and low preHSCT BAALC/ABL1 copy numbers also did not differ significantly in pre-HSCT characteristics; specifically, no significant differences were found regarding the remission status at HSCT, white blood count at time of blood sampling for $B A A L C / A B L 1$ copy number evaluation or time from blood sampling to HSCT (Supplementary Table 1).

\section{Prognostic significance of pre-HSCT $B A A L C /$ $A B L 1$ copy numbers}

Patients with high pre-HSCT BAALC/ABL1 copy numbers had a significantly higher cumulative incidence of relapse (CIR, $P=.02$, Figure $2 \mathrm{~A}$ ) and shorter overall survival (OS, $P=.03$, Figure $2 \mathrm{~B}$ ) which was reproduced when we restricted our analysis to patients with a normal karyotype ( $\mathrm{n}=38, P=.007$ and $P=.11$, respectively, Figures $2 \mathrm{C}$ and 2D). Subgroup analyses for patients harboring $d e$ novo disease ( $\mathrm{n}=52$, Supplementary Figure 2 ), patients transplanted in CR ( $\mathrm{n}=68$, Supplementary Figure 3), CD34-positive AML ( $\mathrm{n}=31$, Supplementary Figure 4), patients surviving longer than 100 days after HSCT ( $\mathrm{n}=71$, Supplementary Figure 5), as well as patients with diagnostic $B A A L C / A B L 1$ copy number information available ( $\mathrm{n}=51$, Supplementary Figure 6$)$ are shown in the Supplementary Materials.

One year after HSCT, $52 \%$ of patients with high preHSCT $B A A L C / A B L 1$ copy numbers relapsed compared to $25 \%$ of patients with low pre-HSCT BAALC/ABL1 copy numbers. Furthermore, $38 \%$ of patients with high preHSCT $B A A L C / A B L 1$ copy numbers were alive compared to $68 \%$ of patients with low pre-HSCT $B A A L C / A B L 1$ copy numbers. Patients with high pre-HSCT BAALC/ABL1 copy numbers suffering relapse had a trend for shorter time to relapse after HSCT (median 78, range 19-244 days) compared to patients with low pre-HSCT $B A A L C / A B L 1$ copy numbers (median 116, range 27-543 days, $P=.07$ ). Furthermore, for patients without non-relapse mortality after 100 days and six months after HSCT, those with high pre-HSCT BAALC/ABL1 copy numbers more often relapsed compared to patients with low pre-HSCT $B A A L C / A B L 1$ copy numbers $(37 \%$ vs. $11 \%, P=.02$ (Figure 3), and $73 \%$ vs. 27\%, $P=.002$, respectively). In multivariable analysis, high pre-HSCT $B A A L C / A B L 1$ copy numbers significantly associated with higher CIR (Hazard Ratio [HR] 2.6, Confidence Interval [CI] 1.2-5.7, $P=.01)$ after adjustment for disease status at HSCT $(P=.003)$ and disease origin $(P=.009)$ and shorter OS (HR 2.1, CI 1.14.1, $P=.03$, Table 2).

Detailed comparisons between the four groups of patients experiencing relapse or remaining in remission with high or low pre-HSCT BAALC/ABL1 copy numbers are shown in the Supplementary Materials.

\section{DISCUSSION}

Assessment of residual disease provides a powerful tool to measure treatment responses and to identify patients at high risk of relapse [4]. Although we still lack data of prospective MRD-guided trials in non-APL (acute promyelocyte leukemia) AML, MRD assessment may allow preemptive therapy to delay or even prevent relapse and improve outcomes [5, 26, 27]. However, about 40\% of AML patients do not harbor the today commonly used molecular MRD targets [3, 4], reflecting a need for new MRD markers.

While the prognostic impact of high $B A A L C$ expression levels at diagnosis has been widely evaluated [3, 16-19], only a few studies with limited patient numbers evaluated $B A A L C$ expression levels during disease course using qRT-PCR [11, 15, 20, 21]. For MRD evaluation in AML in general, it remains unclear whether peripheral blood or bone marrow should be analyzed [7, 28]. For $B A A L C$, high correlations of expression levels in peripheral blood and bone marrow in both newly diagnosed AML patients and healthy individuals have been shown $[15,16]$. While some authors only used bone marrow [21], others used BAALC expression levels of either blood or bone marrow for survival analysis at diagnosis and during disease course $[11,20]$. Peripheral blood is derived faster, with lower risk of complications and a higher convenience for the patient than bone marrow aspiration and results in comparable $B A A L C$ expression data $[15,16]$. Therefore, we decided to restrict our analysis to peripheral blood samples to examine the prognostic impact of absolute pre-HSCT BAALC/ABL1 copy numbers in patients receiving NMA-HSCT.

None of the aforementioned studies focusing on $B A A L C$ expression levels during disease course reported significant diagnostic clinical or genetic associations with different $B A A L C$ expression levels at a defined point in time in CR. In our study, we also did not detect any significant association of high preHSCT BAALC/ABL1 copy numbers with tested pretreatment or pre-HSCT parameters. This may indicate that the observed higher CIR and subsequent shorter OS is indeed driven by residual disease detected by high pre-HSCT $B A A L C / A B L 1$ copy numbers rather than other commonly tested prognostic parameters. The first 
Table 1: Clinical characteristics of $82 \mathrm{AML}$ patients treated with HSCT according to absolute pre-HSCT $B A A L C / A B L 1$ copy numbers (high $v s$. low, 0.14 cut)

\begin{tabular}{|c|c|c|c|c|}
\hline Characteristic & $\begin{array}{l}\text { All patients } \\
\quad(n=82)\end{array}$ & $\begin{array}{c}\text { Low pre-HSCT } \\
B A A L C / A B L 1 \text { copy } \\
\text { numbers }(\mathrm{n}=61)\end{array}$ & $\begin{array}{c}\text { High pre-HSCT } \\
B A A L C / A B L 1 \text { copy } \\
\text { numbers }(\mathrm{n}=21)\end{array}$ & $\boldsymbol{P}$ \\
\hline Pre-HSCT $B A A L C / A B L 1$ copy numbers & & & & $<.001$ \\
\hline Median & 0.03 & 0.02 & 0.44 & \\
\hline Range & $0.00-2.58$ & $0.00-0.11$ & $0.14-2.58$ & \\
\hline Age at HSCT, years & & & & .79 \\
\hline Median & 63.9 & 64.9 & 63.9 & \\
\hline Range & $50.8-76.2$ & $51.5-76.2$ & $50.8-74.9$ & \\
\hline Sex, n $(\%)$ & & & & .80 \\
\hline Male & 37 & $27(44)$ & $10(48)$ & \\
\hline Female & 45 & $34(56)$ & $11(52)$ & \\
\hline Hemoglobin at diagnosis, $\mathrm{g} / \mathrm{dL}$ & & & & .54 \\
\hline Median & 8.7 & 9.0 & 8.5 & \\
\hline Range & $4.5-14.4$ & $5.5-14.4$ & $4.5-11.3$ & \\
\hline Platelet count at diagnosis, $\times 10^{9} / \mathrm{L}$ & & & & .76 \\
\hline Median & 65 & 71 & 63 & \\
\hline Range & $3-224$ & $3-167$ & $13-224$ & \\
\hline WBC count at diagnosis, $\times 10^{9} / \mathrm{L}$ & & & & .13 \\
\hline Median & 7.2 & 4.6 & 22.4 & \\
\hline Range & $0.7-385$ & $0.8-324$ & $0.7-385$ & \\
\hline Blood blasts at diagnosis, $\%$ & & & & .48 \\
\hline Median & 22 & 21 & 28 & \\
\hline Range & $0-97$ & $0-97$ & $2-97$ & \\
\hline BM blasts at diagnosis, $\%$ & & & & .87 \\
\hline Median & 50 & 52 & 43 & \\
\hline Range & $3-95$ & $3-95$ & $10-95$ & \\
\hline Karyotype, n (\%) & & & & .45 \\
\hline Abnormal & 41 & $32(55)$ & $9(43)$ & \\
\hline Normal & 38 & $26(45)$ & $12(57)$ & \\
\hline ELN 2010 Genetic Group, n (\%) [36] & & & & .86 \\
\hline Favorable & 17 & $12(22)$ & $5(26)$ & \\
\hline Intermediate-I & 19 & $13(24)$ & $6(32)$ & \\
\hline Intermediate-II & 19 & $15(27)$ & $4(21)$ & \\
\hline Adverse & 19 & $15(27)$ & $4(21)$ & \\
\hline Disease origin, $\mathrm{n}(\%)$ & & & & .60 \\
\hline De novo & 52 & $40(66)$ & $12(57)$ & \\
\hline Secondary & 30 & $21(34)$ & $9(43)$ & \\
\hline
\end{tabular}




\begin{tabular}{|c|c|c|c|c|}
\hline Characteristic & $\begin{array}{l}\text { All patients } \\
\qquad(\mathrm{n}=\mathbf{8 2})\end{array}$ & $\begin{array}{c}\text { Low pre-HSCT } \\
B A A L C / A B L 1 \text { copy } \\
\text { numbers }(\mathrm{n}=61)\end{array}$ & $\begin{array}{c}\text { High pre-HSCT } \\
B A A L C / A B L 1 \text { copy } \\
\text { numbers }(\mathrm{n}=21)\end{array}$ & $\boldsymbol{P}$ \\
\hline$N P M 1$ at diagnosis, $\mathrm{n}(\%)$ & & & & .76 \\
\hline Wild-type & 51 & $36(77)$ & $15(71)$ & \\
\hline Mutated & 17 & $11(23)$ & $6(29)$ & \\
\hline FLT3-ITD at diagnosis, $\mathrm{n}(\%)$ & & & & 1 \\
\hline Absent & 54 & $38(79)$ & $16(80)$ & \\
\hline Present & 14 & $10(21)$ & $4(20)$ & \\
\hline$C E B P A$ at diagnosis, $\mathrm{n}(\%)$ & & & & .09 \\
\hline Wild-type & 51 & $34(83)$ & $17(100)$ & \\
\hline Mutated & 7 & $7(17)$ & $0(0)$ & \\
\hline
\end{tabular}

$A B L 1$, Abelson murine leukemia viral oncogene homolog 1 gene; $B A A L C$, brain and acute leukemia, cytoplasmatic gene; $\mathrm{BM}$, bone marrow; $C E B P A, \mathrm{CCAAT} /$ enhancer-binding protein alpha gene; ELN, European LeukemiaNet classification 2010; FLT3-ITD, internal tandem duplication of the fms like tyrosine kinase 3 gene; HSCT, hematopoietic stem cell transplantation; NPM1, nucleophosmin 1 gene; WBC, white blood cell.

study to propose $B A A L C$ as a potential MRD marker analyzed 45 patients with de novo acute leukemia, but also included six patients with APL and 11 patients with lymphoid leukemia in their analysis [15]. The authors were able to show a superior disease-free survival in patients with lower $B A A L C / G A P D H$ expression levels in bone marrow after CR achievement. Another small study focused on 45 patients harboring core-binding factor (CBF) AML that received an allogeneic or autologous HSCT and evaluated $B A A L C / A B L 1$ expression levels in bone marrow at diagnosis, as well as in $\mathrm{CR}$ after the first induction cycle, pre-HSCT, and at day 60 postHSCT. While the authors showed significantly shorter OS, event-free survival (EFS) and higher CIR in patients with high $B A A L C / A B L 1$ expression levels at diagnosis and post-HSCT, there was no significant impact on outcome after first induction cycle or pre-HSCT [21]. In contrast, we observed a strong prognostic impact of high pre-HSCT BAALC/ABL1 copy numbers on CIR and OS in univariable and multivariable models. These differences might be explained by a lower patient number $(n=45)$ and/or the restriction to CBF AML in the study of Yoon et al. [21]. In $27 \mathrm{CN}-\mathrm{AML}$ patients with high initial $B A A L C / A B L 1$ expression levels, Weber et al. [11] observed shorter EFS for individuals with sustained high $B A A L C / A B L 1$ expression levels in peripheral blood or bone marrow after two induction cycles. Later, this data was extended to 46 and 33 patients after completion of two induction cycles and 3-6 months after completion of two induction cycles, respectively [11]. Again, patients with high $B A A L C / A B L 1$ expression levels at either of both time points had shorter EFS. Despite this promising data, possible limitations of BAALC as MRD marker still have to be determined. While most studies showed a prognostic impact without a prior assessment of the CD34 expression status [11, 20,21], Najima et al. [15] postulated $B A A L C$ as MRD marker limited to CD34-positive AML as $B A A L C$ is upregulated in CD34-positive AML [14]. Restricting our analysis to patients with CD34-positive AML, we also observed a trend for higher CIR in patients with high pre-HSCT $B A A L C / A B L 1$ copy numbers despite low patient numbers $(P=.06, \quad \mathrm{n}=31$, Supplementary Material). Limited numbers of patients with CD34-negative AML prevented a separate analysis for this subset. However, we observed no difference in CD34-positivity or CD34 expression at diagnosis between patients with high or low pre-HSCT $B A A L C / A B L 1$ copy numbers (Supplementary Table 1). Further studies are needed to evaluate whether there are specific AML subgroups for which $B A A L C$ represents a more suitable MRD marker than for others.

To our knowledge until today all studies used qRTPCR for $B A A L C$ evaluation but different approaches to define a cut-off for high or low $B A A L C$ expression levels during follow-up. Najima et al. [15] used the twofold standard deviation over the median of a healthy cohort, while Yoon et al. [21] focused on the relative $B A A L C / A B L 1$ expression of the tested patients and used a ROC (receiver operation characteristic) curve to define the optimal cut for each point in time individually. The 
latter resembles our approach and - despite different methodology - the evaluated cut-off in our cohort was also slightly higher than the two-fold standard deviation over the median of healthy $B A A L C / A B L 1$ copy numbers in peripheral blood ( 0.14 vs. 0.10 , respectively). Finally, Weber et al. used the median $B A A L C / A B L 1$ expression at diagnosis of the initial cohort [11] to define high or low expression during disease course but restricted their analysis to patients with initially high $B A A L C / A B L 1$ expression levels $[11,20]$. In our study, for a subset of the analyzed patients $(\mathrm{n}=51)$ diagnostic material for $B A A L C / A B L 1$ copy number assessment was available. For patients' characteristic, as well as clinical and biological associations linked with high $B A A L C / A B L 1$ copy numbers at diagnosis see the Supplementary Material. When we restricted our outcome analyses to patients with low or high $B A A L C / A B L 1$ copy numbers at diagnosis - despite the limited number of patients - we observed a trend for higher CIR and shorter OS for patients with high pre-HSCT $B A A L C / A B L 1$ copy numbers in patients irrespective of the diagnostic $B A A L C / A B L 1$ copy number (Supplementary Figure $6)$. In fact five of the patients with low diagnostic $B A A L C / A B L 1$ copy numbers had high pre-HSCT $B A A L C / A B L 1$ copy numbers, of which three subsequently relapsed (see Supplementary Material for details). Thus, despite the limited number of patients, our data indicate that pre-HSCT $B A A L C / A B L 1$ copy
A

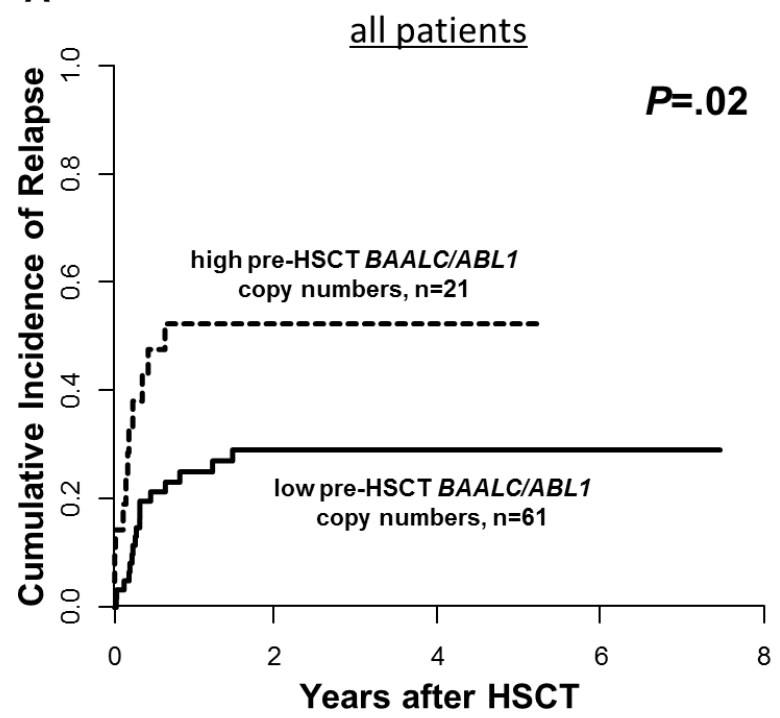

C

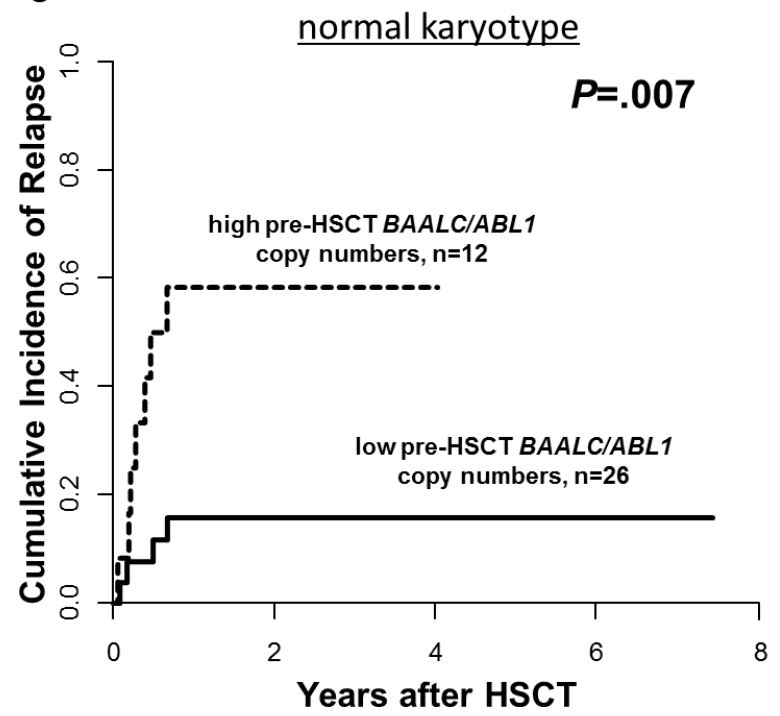

B

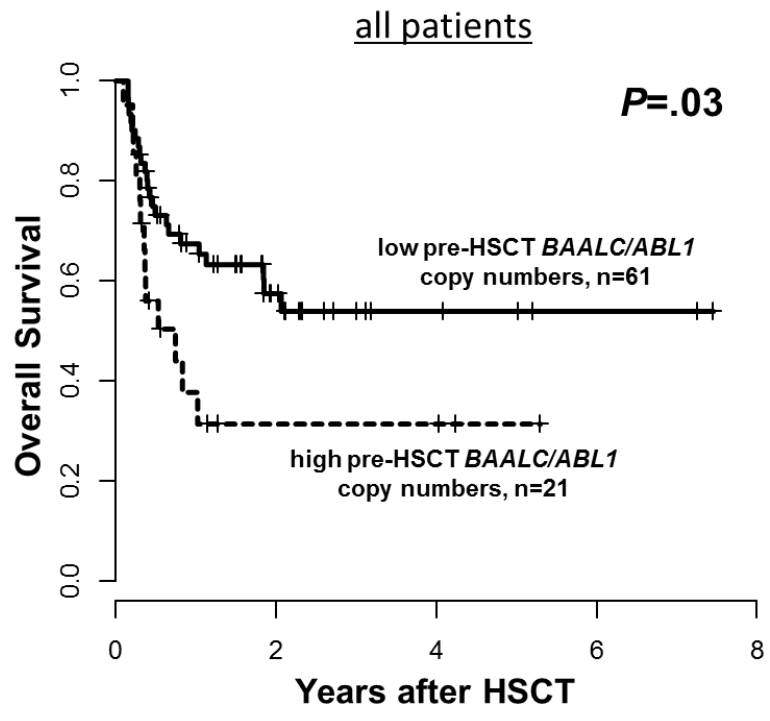

D

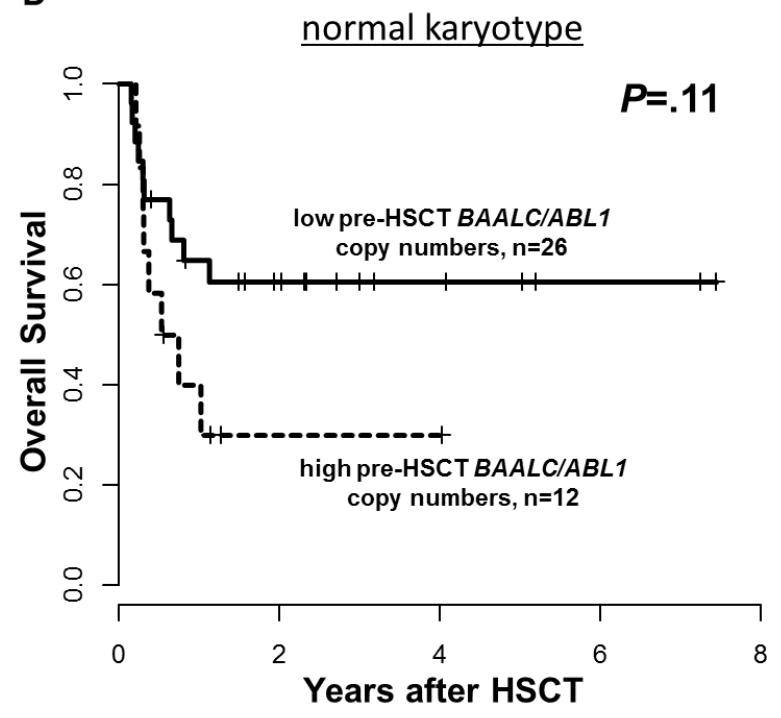

Figure 2: Outcome of patients according to pre-HSCT $B A A L C / A B L 1$ copy numbers, high vs low, 0.14 cut, (A) Cumulative Incidence of Relapse and (B) Overall Survival for the entire set $(\mathrm{n}=82)$ and (C) Cumulative Incidence of relapse and (D) Overall Survival in patients with a normal karyotype $(n=38)$. 
number determination can provide valuable clinical information also in patients with low diagnostic $B A A L C / A B L 1$ copy numbers.

Considering the small number of studies focusing on $B A A L C$ expression as a MRD marker, the optimal cut-off needs validation. However, assessment of $B C R-A B L 1$ as MRD marker in CML showed us the technical difficulties of standard curves and in achieving an inter-laboratory comparability to ensure consistent analyses [22]. ddPCR has already been shown to provide comparable sensitivity to qRT-PCR but seems to have an improved day-to-day reproducibility and greater precision [23, 29, Huang et al, ASH 2015]. Therefore, ddPCR may represent a promising new method for gene expression analyses for MRD monitoring in the future.

Our here presented study is the first to demonstrate that ddPCR is a feasible method for evaluation of absolute $B A A L C / A B L 1$ copy numbers prior to allogeneic HSCT. We were able to show that patients with high pre-HSCT $B A A L C / A B L 1$ copy numbers had a significant higher CIR and shorter OS $(P=.02$ and $P=.03$, respectively, Figure 2). Patients with high preHSCT BAALC/ABL1 copy numbers had an over 2.5 -fold higher risk of relapse and an over 2-fold higher risk of death after HSCT compared to patients with low preHSCT BAALC/ABL1 copy numbers (Table 2). Patients with high pre-HSCT $B A A L C / A B L 1$ copy numbers more often suffered relapse within the first 100 days after HSCT ( $37 \%$ vs. $11 \%, P=.02)$ and the time from HSCT to relapse was shorter in patients with high preHSCT $B A A L C / A B L 1$ copy numbers by trend $(P=.07$, Figure 3 ). To our knowledge, no other study reported on early relapses detected by high $B A A L C$ expression levels. We postulate that high pre-HSCT $B A A L C / A B L 1$ copy numbers might indicate a residual disease burden in AML patients that subsequently may lead to early relapse during follow-up. Noteworthy, for all patients, peripheral blood was used in the analyses facilitating repetitive MRD assessment. We and others [11, 15, 20, $21]$ were able to show that $B A A L C$ has the potential to allow further risk stratification during disease course and subsequently may improve MRD assessment in addition to other established MRD markers such as PML-RARA, CBFB-MYH11, RUNX1-RUNXIT1 or NPM1 mutations. Furthermore, since $B A A L C$ is expressed at different amounts in all AML patients, it might allow molecular MRD detection in patients lacking molecular alterations commonly used for MRD assessment.

Restrictions of our study are the retrospective nature and the limited patient numbers. Future prospective clinical trials are needed to validate the here-established cut-off value and the resulting outcome findings in larger patient populations.

Even with a variety of possible treatment options such as reduction of immunosuppression, donor lymphocyte infusions or treatment with hypomethylating agents, patients suffering from morphologic relapse after HSCT have a very poor prognosis $[25,30,31]$. Pre-HSCT BAALC/ABL1 copy number evaluation allows early identification of patients at higher risk of relapse and subsequently closer monitoring for relapse in the post-transplant period. In the future pre-HSCT $B A A L C / A B L 1$ evaluation might guide preemptive treatment to improve the poor prognosis of AML patients with a risk for morphologic relapse. Furthermore, prospective studies will be required to evaluate whether AML patients with high pre-HSCT BAALC/ABL1 copy numbers might benefit from additional treatment or intensification of the conditioning regimen prior to allogeneic HSCT.

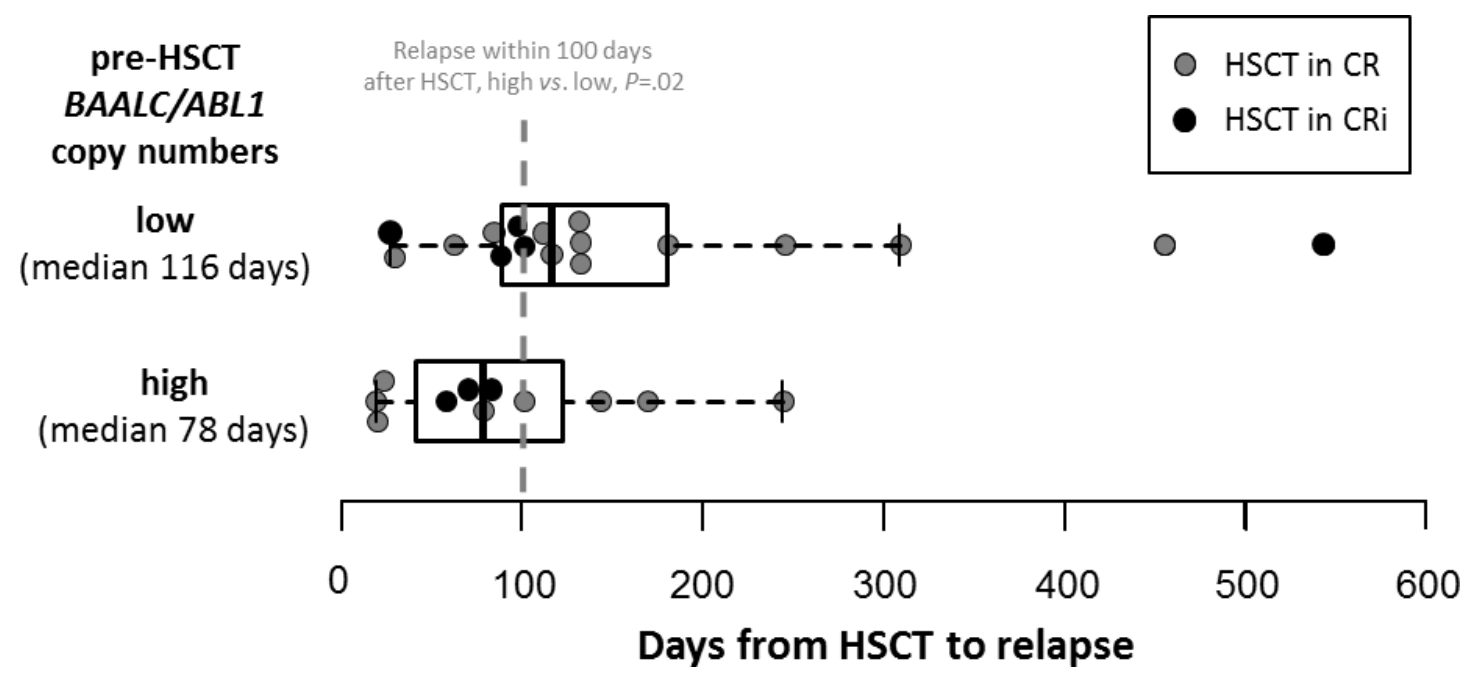

Figure 3: Time from HSCT to relapse according to high (median 78, range 19-244 days) or low (median 116, range 27-543 days) absolute pre-HSCT $B A A L C / A B L 1$ copy numbers in relapsed patients $(\mathrm{n}=\mathbf{2 8})$. 
Table 2: Multivariable outcome analyses of 82 AML patients treated with HSCT

\begin{tabular}{|c|c|c|c|c|}
\hline \multirow{2}{*}{ Variable } & \multicolumn{2}{|c|}{ Cumulative Incidence of Relapse } & \multicolumn{2}{|c|}{ Overall survival } \\
\hline & $H_{R}^{a}(95 \%$ CI $)$ & $\boldsymbol{P}$ & $\mathrm{HR}^{\mathrm{a}}(95 \% \mathrm{CI})$ & $\boldsymbol{P}$ \\
\hline $\begin{array}{l}\text { pre-HSCT } B A A L C / A B L 1 \text { copy numbers } \\
\text { (high } v s . \text { low, } 0.14 \text { cut) }\end{array}$ & $2.6(1.2-5.7)$ & .012 & $2.1(1.1-4.1)$ & .03 \\
\hline Disease origin (de novo vs. secondary) & $0.4(0.2-0.8)$ & .009 & - & - \\
\hline Disease status at HSCT (CR vs. CRi) & $0.3(0.1-0.7)$ & .003 & - & - \\
\hline
\end{tabular}

$A B L 1$, Abelson murine leukemia viral oncogene homolog 1 gene; $B A A L C$, brain and acute leukemia, cytoplasmatic gene; $\mathrm{CI}$, confidence interval; $\mathrm{CR}$, complete remission; $\mathrm{CRi}$, CR with incomplete peripheral recovery; HSCT, hematopoietic cell transplantation; HR, hazard ratio.

${ }^{a} \mathrm{HR}$, hazard ratio, $<1(>1)$ indicate lower (higher) risk for an event for the first category listed for the dichotomous variables.

Variables considered in the models were those significant at $\alpha=0.20$ in univariable analyses. For OS endpoint, variables considered were hemoglobin count at diagnosis, white blood cell count at diagnosis, pre-HSCT BAALC/ABL1 copy numbers (high vs. low) and HLA match (antigen match vs mismatch) while for CIR endpoint, variables considered were disease origin (de novo vs. secondary), BAALC/ABL1 copy numbers (high vs. low), disease status at HSCT (CR vs. CRi) and ELN 2010 Genetic Group.

\section{MATERIALS AND METHODS}

\section{Patients and treatment}

A total of 82 adult AML patients who received allogeneic HSCT at the University of Leipzig between September 2002 and December 2015 were retrospectively included in this analysis. All patients had peripheral blood samples up to 14 days prior to HSCT (median 7, range 0-14 days) for $B A A L C / A B L 1$ copy number assessment available. White blood count (WBC) was assessed at time of blood sampling for analysis. Additionally, for 51 of these patients diagnostic peripheral blood or bone marrow samples were available for $B A A L C / A B L 1$ copy number analysis. For details see Supplementary Materials and Supplementary Table 3.

All patients received age-dependent cytarabine based chemotherapy protocols (under or over 60 years) and were consolidated with HSCT in first $(60 \%)$ or second CR $(23 \%)$ or CRi (17\%). For details please see Supplementary Materials. Median age at HSCT was 63.9 (range 50.8-76.2) years. Written informed consent for participation in these studies was obtained in accordance with the Declaration of Helsinki.

All patients received NMA conditioning with fludarabine $30 \mathrm{mg} / \mathrm{m}^{2}$ for three days followed by $2 \mathrm{~Gy}$ total body irradiation $[32,33]$ and infusion of granulocyte colony stimulating factor (G-CSF)-mobilized peripheral blood stem cells on day 0 . Reasons for choosing a NMA protocol were age over 50 years for patients receiving unrelated HSCT $(\mathrm{n}=71)$ or age over 55 years for patients receiving related HSCT $(n=11)$. Patients' characteristics are shown in Table 1 and Supplementary Table 1. For Information regarding prevention and incidence of acute and chronic graft-versus-host disease see Supplementary Material. Median follow-up after HSCT for patients alive was 1.8 years.

\section{Healthy control cohort}

In a control cohort of 7 healthy volunteers (median age of 62.7, range 39.6-82.0 years), absolute $B A A L C / A B L 1$ copy numbers in peripheral blood were evaluated. Written informed consent was obtained for all healthy individuals; their characteristics are shown in Supplementary Table 2.

\section{Cytogenetic, moleculargenetic, and flow cytometric analyses}

At diagnosis, cytogenetic analyses, the presence of internal tandem duplication in the FLT3 gene (FLT3ITD) as well as mutations in the FLT3 tyrosine kinase domain (FLT3-TKD), NPM1 and CEBPA genes were determined as previously described [34]. For details see Supplementary Material. For patients with material available, the CD34 and CD38 expression on mononuclear cells in bone marrow at diagnosis was determined as previously described [35].

\section{ddPCR assessment of $B A A L C / A B L 1$ copy numbers}

Absolute BAALC copy numbers were assessed using a specific ddPCR assay (BioRad, Hercules, 
California, USA; Assay ID: dHsaCPE5025566) according to manufacturer's specifications. Primers and probe sequences for $A B L 1$ copy number assessment (Biomers, Ulm, Germany) are shown in the Supplementary Material. ddPCR was performed on a QX100 platform (BioRad) and QuantaSoft software (Biorad) was used for raw data processing. With the droplet generator, each sample was divided into approximately 10,000 - 20,000 partitions (droplets). After PCR amplification (for details see Supplementary Material) the samples were placed into the droplet reader, where each droplet was read as positive or negative for the gene expression by issuing specific fluorescence signals (FAM and HEX). Redistribution according to the Poisson's algorithm determined the target copy number in the original sample. Two examples of the ddPCR droplet reader output are given in Supplementary Figure 1.

\section{$B A A L C / A B L 1$ cut-off point definition}

Using the $\mathrm{R}$ package 'OptimalCutpoints' a cutoff point of 0.1397 absolute pre-HSCT $B A A L C / A B L 1$ copies was determined and used to define patients with high $(\mathrm{n}=21,26 \%)$ and low $(\mathrm{n}=61,74 \%)$ pre-HSCT $B A A L C / A B L 1$ copy numbers in peripheral blood. For details see Supplementary Materials.

\section{End points and statistical analyses}

For definition of clinical endpoints and statistical analyses for associations and survival (univariable and multivariable) see Supplementary Materials.

\section{Author contributions}

MJ and SS contributed to the design and analysis of this study and the writing of the manuscript, and all authors agreed on the final version. $\mathrm{MJ}, \mathrm{MB}, \mathrm{KG}, \mathrm{JS}, \mathrm{JG}, \mathrm{JH}$ and SB carried out the laboratory-based research; MJ and SS performed statistical analyses; and MJ, WP, GNF, VV, GB, TL, DN and SS were involved directly or indirectly in the care of patients and/or sample procurement.

\section{ACKNOWLEDGMENTS}

The authors thank Christel Müller, Daniela Bretschneider, Evelin Hennig, Sabine Leiblein, Martina Pleß, Ulrike Bergmann, Janet Bogardt, Annette Jilo, and Dagmar Cron for their help in determing cytogenetic, morphologic and immunological analyses, and Christine Günther, Scarlett Schwabe, Ines Kovacs, and Kathrin Wildenberger for their help in sample processing.

\section{CONFLICTS OF INTEREST}

The authors declare no conflicts of interest.

\section{FUNDING}

This study was supported by the Deutsche José Carreras Stiftung e.V. (04R/2016 and PS15/15), the Verein Zusammen gegen den Krebs e.V., and Ein Herz für Kinder e.V.

\section{REFERENCES}

1. Döhner H, Weisdorf DJ, Bloomfield CD. Acute Myeloid Leukemia. N Engl J Med. 2015; 373:1136-1152.

2. Döhner H, Estey E, Grimwade D, Amadori S, Appelbaum FR, Büchner T, Dombret H, Ebert BL, Fenaux P, Larson RA, Levine RL, Lo-Coco F, Naoe T, et al. Diagnosis and management of AML in adults: 2017 ELN recommendations from an international expert panel. Blood. 2017; 129:424-447.

3. Grimwade D, Freeman SD. Defining minimal residual disease in acute myeloid leukemia: which platforms are ready for "prime time"? Blood. 2014; 124:3345-3355.

4. Freeman SD, Jovanovic JV, Grimwade D. Development of minimal residual disease-directed therapy in acute myeloid leukemia. Semin Oncol. 2008; 35:388-400.

5. Ivey A, Hills RK, Simpson MA, Jovanovic JV, Gilkes A, Grech A, Patel Y, Bhudia N, Farah H, Mason J, Wall K, Akiki S, Griffiths M, et al. Assessment of Minimal Residual Disease in Standard-Risk AML. N Engl J Med. 2016; 374:422-433.

6. Freeman SD, Virgo P, Couzens S, Grimwade D, Russell N, Hills RK, Burnett AK. Prognostic relevance of treatment response measured by flow cytometric residual disease detection in older patients with acute myeloid leukemia. J Clin Oncol. 2013; 31:4123-4131.

7. Buccisano F, Maurillo L, Del Principe MI, Del Poeta G, Sconocchia G, Lo-Coco F, Arcese W, Amadori S, Venditti A. Prognostic and therapeutic implications of minimal residual disease detection in acute myeloid leukemia. Blood. 2012; 119:332-341.

8. Buckley SA, Wood BL, Othus M, Hourigan CS, Ustun C, Linden MA, DeFor TE, Malagola M, Anthias C, Valkova V, Kanakry CG, Gruhn B, Buccisano F, et al. Minimal residual disease prior to allogeneic hematopoietic cell transplantation in acute myeloid leukemia: a meta-analysis. Haematologica. 2017; 102:865-873.

9. Ommen HB, Schnittger S, Jovanovic JV, Ommen IB, Hasle H, Østergaard M, Grimwade D, Hokland P. Strikingly different molecular relapse kinetics in NPM1c, PML-RARA RUNX1-RUNX1T1, and CBFB-MYH11 acute myeloid leukemias. Blood. 2010; 115:198-205.

10. Huang S, Yang H, Li Y, Feng C, Gao L, Chen GF, Gao HH, Huang Z, Li YH, Yu L. Prognostic Significance of MixedLineage Leukemia (MLL) Gene Detected by Real-Time Fluorescence Quantitative PCR Assay in Acute Myeloid Leukemia. Med Sci Monit. 2016; 22:3009-3017. 
11. Weber S, Alpermann T, Dicker F, Jeromin S, Nadarajah N, Eder C, Fasan A, Kohlmann A, Meggendorfer M, Haferlach C, Kern W, Haferlach T, Schnittger S. BAALC expression: a suitable marker for prognostic risk stratification and detection of residual disease in cytogenetically normal acute myeloid leukemia. Blood Cancer J. 2014;4:e173.

12. Ostergaard M, Olesen LH, Hasle H, Kjeldsen E, Hokland P. WT1 gene expression: an excellent tool for monitoring minimal residual disease in $70 \%$ of acute myeloid leukaemia patients - results from a single-centre study. Br J Haematol. 2004; 125:590-600.

13. Ding L, Ley TJ, Larson DE, Miller CA, Koboldt DC, Welch JS, Ritchey JK, Young MA, Lamprecht T, McLellan MD, McMichael JF, Wallis JW, Lu C, et al. Clonal evolution in relapsed acute myeloid leukaemia revealed by wholegenome sequencing. Nature. 2012; 481:506-510.

14. Baldus CD, Tanner SM, Kusewitt DF, Liyanarachchi S, Choi C, Caligiuri MA, Bloomfield CD, de la Chapelle A. BAALC, a novel marker of human hematopoietic progenitor cells. Exp Hematol. 2003; 31:1051-1056.

15. Najima Y, Ohashi K, Kawamura M, Onozuka Y, Yamaguchi T, Akiyama H, Sakamaki H. Molecular monitoring of $B A A L C$ expression in patients with CD34-positive acute leukemia. Int J Hematol. 2010; 91:636-45.

16. Bienz M, Ludwig M, Leibundgut EO, Mueller BU, Ratschiller D, Solenthaler M, Fey MF, Pabst T. Risk assessment in patients with acute myeloid leukemia and a normal karyotype. Clin Cancer Res. 2005; 11:1416-1424.

17. Langer C, Radmacher MD, Ruppert AS, Whitman SP, Paschka P, Mrózek K, Baldus CD, Vukosavljevic T, Liu CG, Ross ME, Powell BL, de la Chapelle A, Kolitz JE, et al. High BAALC expression associates with other molecular prognostic markers, poor outcome, and a distinct gene expression signature in cytogenetically normal patients younger than 60 years with acute myeloid leukemia: a Cancer and Leukemia Group B (CALGB) study. Blood. 2008; 111:5371-5379.

18. Metzeler KH, Dufour A, Benthaus T, Hummel M, Sauerland MC, Heinecke A, Berdel WE, Büchner T, Wörmann B, Mansmann U, Braess J, Spiekermann K, Hiddemann W, et al. ERG Expression Is an Independent Prognostic Factor and Allows Refined Risk Stratification in Cytogenetically Normal Acute Myeloid Leukemia: A Comprehensive Analysis of ERG, MN1, and BAALC Transcript Levels Using Oligonucleotide Microarrays. J Clin Oncol. 2009; 27:5031-5038.

19. Schwind S, Marcucci G, Maharry K, Radmacher MD, Mrózek K, Holland KB, Margeson D, Becker H, Whitman $\mathrm{SP}, \mathrm{Wu}$ YZ, Metzeler KH, Powell BL, Kolitz JE, et al. $B A A L C$ and $E R G$ expression levels are associated with outcome and distinct gene and microRNA expression profiles in older patients with de novo cytogenetically normal acute myeloid leukemia: a Cancer and Leukemia Group B study. Blood. 2010; 116:5660-5669.
20. Weber S, Haferlach T, Alpermann T, Perglerová K, Schnittger S, Haferlach C, Kern W. Feasibility of BAALC gene expression for detection of minimal residual disease and risk stratification in normal karyotype acute myeloid leukaemia. Br J Haematol. 2016; 175:904-916.

21. Yoon JH, Kim HJ, Shin SH, Yahng SA, Lee SE, Cho BS, Eom KS, Kim YJ, Lee S, Min CK, Cho SG, Kim DW, Lee JW, et al. BAALC and WT1 expressions from diagnosis to hematopoietic stem cell transplantation: consecutive monitoring in adult patients with core-binding-factor positive AML. Eur J Haematol. 2013; 91:112-121.

22. Müller MC, Cross NCP, Erben P, Schenk T, Hanfstein B, Ernst T, Hehlmann R, Branford S, Saglio G, Hochhaus A. Harmonization of molecular monitoring of CML therapy in Europe. Leukemia. 2009; 23:1957-1963.

23. Hindson CM, Chevillet JR, Briggs HA, Gallichotte EN, Ruf IK, Hindson BJ, Vessella RL, Tewari M. Absolute quantification by droplet digital PCR versus analog realtime PCR. Nat Methods. 2013; 10:1003-1005.

24. Horowitz MM, Gale RP, Sondel PM, Goldman JM, Kersey J, Kolb HJ, Rimm AA, Ringdén O, Rozman C, Speck B. Graft-versus-leukemia reactions after bone marrow transplantation. Blood. 1990; 75:555-562.

25. Bethge WA, Storer BE, Maris MB, Flowers ME, Maloney DG, Chauncey TR, Woolfrey AE, Storb R, Sandmaier BM. Relapse or progression after hematopoietic cell transplantation using nonmyeloablative conditioning: effect of interventions on outcome. Exp Hematol. 2003; 31:974-980.

26. Rubnitz JE, Inaba $\mathrm{H}$, Dahl $\mathrm{G}$, Ribeiro RC, Bowman WP, Taub J, Pounds S, Razzouk BI, Lacayo NJ, Cao X, Meshinchi S, Degar B, Airewele G, et al. Minimal residual disease-directed therapy for childhood acute myeloid leukaemia: results of the AML02 multicentre trial. Lancet Oncol. 2010; 11:543-552.

27. Doubek M, Palasek I, Pospisil Z, Borsky M, Klabusay M, Brychtova Y, Jurcek T, Jeziskova I, Krejci M, Dvorakova $\mathrm{D}$, Mayer J. Detection and treatment of molecular relapse in acute myeloid leukemia with $R U N X 1$ (AML1), CBFB, or $M L L$ gene translocations: frequent quantitative monitoring of molecular markers in different compartments and correlation with WT1 gene expression. Exp Hematol. 2009; 37:659-672.

28. Hokland P, Ommen HB. Towards individualized follow-up in adult acute myeloid leukemia in remission. Blood. 2011; 117:2577-2584.

29. Della Starza I, Nunes V, Cavalli M, De Novi LA, Ilari C, Apicella V, Vitale A, Testi AM, Del Giudice I, Chiaretti S, Foà R, Guarini A. Comparative analysis between RQ-PCR and digital-droplet-PCR of immunoglobulin/T-cell receptor gene rearrangements to monitor minimal residual disease in acute lymphoblastic leukaemia. Br J Haematol. 2016; 174:541-549.

30. Rautenberg C, Nachtkamp K, Dienst A, Schmidt PV, Heyn C, Kondakci M, Germing U, Haas R, Kobbe G, Schroeder 
T. Sorafenib and Azacitidine as salvage therapy for relapse of FLT3-ITD mutated AML after allo-SCT. Eur J Haematol. 2016; 98:348-354.

31. Schroeder T, Rachlis E, Bug G, Stelljes M, Klein S, Steckel NK, Wolf D, Ringhoffer M, Czibere A, Nachtkamp K, Dienst A, Kondakci M, Stadler M, et al. Treatment of acute myeloid leukemia or myelodysplastic syndrome relapse after allogeneic stem cell transplantation with azacitidine and donor lymphocyte infusions - a retrospective multicenter analysis from the German Cooperative Transplant Study Group. Biol Blood Marrow Transplant. 2015; 21:653-660.

32. McSweeney PA, Niederwieser D, Shizuru JA, Sandmaier BM, Molina AJ, Maloney DG, Chauncey TR, Gooley TA, Hegenbart U, Nash RA, Radich J, Wagner JL, Minor S, et al. Hematopoietic cell transplantation in older patients with hematologic malignancies: replacing high-dose cytotoxic therapy with graft-versus-tumor effects. Blood. 2001; 97:3390-3400.

33. Hegenbart U, Niederwieser D, Sandmaier BM, Maris MB, Shizuru JA, Greinix H, Cordonnier C, Rio B, Gratwohl A, Lange T, Al-Ali H, Storer B, Maloney D, et al. Treatment for acute myelogenous leukemia by low-dose, total-body, irradiation-based conditioning and hematopoietic cell transplantation from related and unrelated donors. J Clin Oncol. 2006; 24:444-453.

34. Bill M, Jentzsch M, Grimm J, Schubert K, Lange T, Cross M, Behre G, Vucinic V, Pönisch W, Franke GN, Niederwieser D, Schwind S. Prognostic impact of the European LeukemiaNet standardized reporting system in older AML patients receiving stem cell transplantation after non-myeloablative conditioning. Bone Marrow Transplant. 2017; 52:932-935.

35. Jentzsch M, Bill M, Nicolet D, Leiblein S, Schubert K, Pless M, Bergmann U, Wildenberger K, Schuhmann L, Cross M, Pönisch W, Franke GN, Vucinic V, et al. Prognostic Impact of the CD34+/CD38- Cell Burden in Patients with Acute Myeloid Leukemia receiving Allogeneic Stem Cell Transplantation. Am J Hematol. 2017; 92:388-396.

36. Döhner H, Estey EH, Amadori S, Appelbaum FR, Büchner T, Burnett AK, Dombret H, Fenaux P, Grimwade D, Larson RA, Lo-Coco F, Naoe T, Niederwieser D, et al. Diagnosis and management of acute myeloid leukemia in adults: Recommendations from an international expert panel, on behalf of the European Leukemia-Net. Blood. 2010; 115:453-474. 